\title{
Saccharification of Ulva lactuca via Pseudoalteromonas piscicida for biofuel production
}

\author{
El-Naggar M. M. ${ }^{1}$, Abdul-Raouf U. M. ${ }^{2}$, Ibrahim H. A. H. ${ }^{1}$, El-Sayed W. M. M. ${ }^{3,}$ \\ ${ }^{1}$ Microbiology Lab., Environ. Div., National Institute of Oceanography and Fisheries (NIOF), Alexandria, Egypt \\ ${ }^{2}$ Botany and Microbiology Department, Faculty of Science, Al-Azhar University-Assuit Branch. Egypt \\ ${ }^{3}$ Microbiology Lab., Environ. Div., National Institute of Oceanography and Fisheries (NIOF), Hurghada, Egypt
}

\section{Email address:}

mmelnaggar@yahoo.com (M. M. El-Naggar), oabdulraouf@yahoo.com (U. M. Abdul-Raouf),

drhassan1973@yahoo.com (H. A. H. Ibrahim),walled_mohamed78@yahoo.com (W. M. M. El-Sayed)

\section{To cite this article:}

El-Naggar M. M., Abdul-Raouf U. M., Ibrahim H. A. H., El-Sayed W. M. M.. Saccharification of Ulva Lactuca Via Pseudoalteromonas

Piscicida for Biofuel Production. Journal of Energy and Natural Resources. Vol. 3, No. 6, 2014, pp. 77-84.

doi: $10.11648 /$ j.jenr.20140306.11

\begin{abstract}
Pseudoalteromonas piscicida WM21 was isolated from seawater at Hurghada, Red Sea, Egypt. It was promising to hydrolyze the polysaccharides of Ulva lactuca. Ulva lactuca contained 44\% carbohydrates, 5\% lipids, 16\% proteins, $12 \%$ Fibers and $23 \%$ ash. Optimization of reducing sugars production by $P$. piscicida WM21 was investigated using PlackettBurmman design. The main effect data as well as the $t$-test results suggested that the beef extract and inoculum size are the most effective variables that controlled the reducing sugar produced by $P$. piscicida. Considerable positive effects of the high levels of substrate concentration and low levels of incubation period were also suggested. On the other hand, variations within the examined levels of $\mathrm{pH}$ levels, $\mathrm{NaCl}$ and peptone recorded slight effects. While the main effect data as well as the $t$-test results suggested that the substrate concentration and incubation period were the most effective variables that controlled amylase activity produced by $P$. piscicida. To evaluate the accuracy of the applied Plackett-Burman statistical design, a verification experiment was carried out. The predicted near optimum and far from optimum levels of the independent variables were examined and compared to the basal condition settings. The applied near optimum condition, resulted in approximately $56 \mathrm{mg} / \mathrm{g}$ increase in reducing sugar with $6 \mathrm{~mm}$ amylase activity by $P$. piscicida when compared to the basal medium formulation, while the conditions predicted to be far from optimal recorded approximately $45 \mathrm{mg} / \mathrm{g}$ decreases in reducing sugar with $3 \mathrm{~mm}$ amylase activity. These results supported the predictions of the applied Plackett-Burman experiment for enhancement of reducing sugar production by marine microorganisms.
\end{abstract}

Keywords: Reducing sugar, Ulva lactuca, Pseudoalteromonas piscicida, Saccharification process, Biofuel

\section{Introduction}

Conversion of biomass from marine algae into ethanol could be economically feasible since some algae hydrolysate can contain more total carbohydrate and hexose sugars than some terrestrial, lignocellulosic biomass feedstock (Philippidis et al., 1993; Chynoweth, 2002; Sluiter, 2006; John et al., 2011). The green macroalgae (chlorophyceae), like Ulva lactuca has been considered as a potential aquatic energy crop as early as in the Aquatic Species Program in the USA back in 1978-1996, due to its high potential growth rates and high content of carbohydrates (Ryther et al., 1984). The process of breaking a complex carbohydrate into its monosaccharide components is called saccharification process. Marine bacteria act a vital role in production of industrial enzymes. Marine bacterial enzymes have several advantages for industrial utilization (Ventosa and Nieto, 1995; Hong et al., 2013; Koppram et al., 2013). Statistical experimental designs are powerful tools for searching the key factors rapidly from a multivariable system and minimizing the error in determining the effect of parameters and the results are achieved in an economical manner (El-Helow and El-Ahawany, 1999; Xiong et al., 2008). The application of statistically based experimental designs is a more efficient approach to deal with a large number of variables (Ooijkaas et al., 1998). Using the Plackett-Burman experimental 
designs has resulted in increased optimization of fermentation titers, and an ability to predict the presence of mixtures and to select substitutes for complex medium ingredients (Monaghan and Koupal, 1989). The PlackettBurman experimental design, a fractional factorial design (Plackett and Burman; 1946, Yu et al., 1997) was applied in this research to reflect the relative importance of various environmental factors on the saccharification process in liquid cultures. The current study was suggested for enhancing the ability of isolated marine bacteria to hydrolyze the polysaccharides of Ulva lactuca by Plackett-Burman experimental designs.

\section{Material and Methods}

\subsection{Sample Collection}

Sea water and sediment samples were collected from marine environment at Hurghada coastline, Red Sea, Egypt, summer 2011. While Ulva lacttuca were harvested from Red Sea, Egypt coastline, to be used as substrates of reducing sugars production.

\subsection{Screening of Hydrolysis Enzymes Producing Marine Bacteria}

Isolation of marine bacteria from the seawater and sediment samples was performed by serial dilution and spread plate method. A volume of $1 \mathrm{ml}$ of each dilution was transferred aseptically to starch nutrient agar plates containing: starch; $10 \mathrm{~g} / \mathrm{L}$ and nutrient agar; $23 \mathrm{~g} / \mathrm{L}$. The plates were incubated at $30^{\circ} \mathrm{C} \pm 2{ }^{\circ} \mathrm{C}$ for $24 \mathrm{~h}$. Tooth picking technique was used to test the ability of isolated bacteria to produce amylase (Margesin et al., 2003). The plates were stabbed consequently using a sterile clean tooth pick in each time with a single colony of each of the tested bacteria. After 3 days the stabbed plates were flooded with iodine solution for detecting the amylase enzyme (Horikoshi, 1999).

\subsection{Phenotypic Characterization of the Promising Marine Bacterial Isolate}

Phenotypic characteristics such as Gram's staining, motility, cultural characteristics, catalase, oxidase and IMViC test of the marine bacterial isolate was studied by adopting standard procedures. Effect of sodium chloride, $\mathrm{pH}$ level, and temperature on growth was tested.

\subsection{Electron Microscope Investigation}

For scanning electron microscopy (SEM), bacterial cells, grown in S.N.B medium, were harvested by mild centrifugation, washed with phosphate buffer $\mathrm{pH} 8$ and fixed with $2 \%$ glutaraldehyde followed by $1 \%$ osmium tetroxide treatment. After completion of fixation, sample was washed in buffer solution, and the washed cells were dehydrated in ascending order of ethanol concentrations. The sample was dried completely in a critical point dryer, and finally coated with gold in JEOL-JFG1100 E ion-sputter-coater. The specimen was viewed in JEOL-JSM 5300 scanning electron microscope operated at $20 \mathrm{kV}$ with a beam specimen angle of $45^{\circ}$.

\subsection{Genotypic Characterization the Promising Marine Bacterial Isolate}

The promising bacterial isolate was cultured in $\mathrm{SN}$ liquid medium for 2 days and genomic DNAs were extracted with genomic DNA extraction protocol of GeneJet genomic DNA purification Kit (Fermentas). PCR using Maxima Hot Start PCR Master Mix (Fermentas) and PCR clean up to the PCR product was performed using GeneJETTM PCR Purification Kit (fermentas). The sequencing to the PCR product on GATC Company was made by using ABI 3730xl DNA sequencer by using universal primaries (16S $27 \mathrm{~F}$ and $16 \mathrm{~S}$ 1492R) Table 1.

Table 1. The primers used in PCR amplification and sequencing.

\begin{tabular}{ll}
\hline Primers & Sequence (5` to 3`) \\
\hline 16 S $27 \mathrm{~F}$ & AGAGTTTGATCCTGGCTCAG \\
$16 \mathrm{~S} 1492 \mathrm{R}$ & GGTTACCTTGTTACGACTT \\
\hline
\end{tabular}

\subsection{Chemical Composition of Ulva Lactuca}

Humidity, organic matter and ash were determined by standard methods (Pádua et al., 2004). Protein content was measured with Kjeldahl method using a factor of $\mathrm{N}=6.25$ (AOAC, 2000; method 976.05). Lipid content was determined with the Soxhlet method (AOAC, 2000; method 920.39). Subtraction of the sum of humidity, protein, lipids, fibers and ash values from 100 was the carbohydrate contents in percentage (Pádua et al., 2004).

\subsection{Pretreatment of Ulva Lactuca}

The algal sample was dried at $70^{\circ} \mathrm{C}$ over night. All dried algae were milled using a laboratory hammer mill in order to obtain a chip size less than $0.2 \mathrm{~mm}$. the dilute acid pretreatment of biomass was optimized at $121^{\circ} \mathrm{C}$ in an autoclave for with sulfuric acid concentrations $1 \mathrm{~N}$, w/v for one hour (Taherzadeh and Karimi, 2008).

\subsection{The Saccharification Medium}

The saccharification process was carried out using medium containing pretreated substrate. A volume of $100 \mathrm{ml}$ of sterile starch nutrient broth medium was added to $3 \mathrm{~g}$ from pretreated substrate as sole carbon source and inoculated with $3 \mathrm{ml}$ freshly prepared inoculum of bacteria. The flasks were loaded on a rotary shaker incubator at a speed of $120 \pm$ $2 \mathrm{rpm}$ at $30 \pm 2^{\circ} \mathrm{C}$ for $24 \mathrm{~h}$. After incubation, the production broths were centrifuged at $5000 \mathrm{rpm}$ for $15 \mathrm{~min}$. The supernatants were collected for determining the reducing sugars concentration and enzymatic activity.

\subsection{Estimation of Reducing Sugars}

The amount of reducing sugars was estimated by dinitrosalicylic acid (DNSA) method (Miller, 1959). 


\subsection{Optimization of Saccharification Process by Experimental Design}

Seven independent variables were screened in nine combinations organized according to the Plackett-Burman design matrix. For each variable, a high (+) and low (-) level was tested. The factors tested were given in Table 2 . All trials were performed in duplicates and the averages of observation results were treated as the responses. The main effect of each variable was determined using the following equation:

$$
E_{\mathrm{xj}}=\left(\mathrm{M}_{\mathrm{i}+}-\mathrm{M}_{\mathrm{i}-}\right) / \mathrm{N}
$$

Where $E_{x j}$ is the variable main effect, $M_{i+}$ and $M_{j-}$ are enzyme activity \& reducing sugar (glucose conc.) in trials where the independent variable (xi) was present in high and low levels, respectively, and $\mathrm{N}$ is the number of trials divided by 2 . A main effect figure with a positive sign indicates that the high level of this variable is nearer to optimum. Using Microsoft Excel, statistical $t$-values for equal unpaired samples were calculated for determination of variable significance (Plackett and Burman; 1946, Yu et al., 1997).

Table 2. Factors examined as independent variables affecting the production of enzymes production by P. piscicida and its levels in the Plackett-Burman experiment.

\begin{tabular}{lllll}
\hline \multirow{2}{*}{ Factor } & Symbol & \multicolumn{2}{l}{ Level } & \\
\cline { 3 - 5 } & & $\mathbf{- 1}$ & $\mathbf{0}$ & $\mathbf{+ 1}$ \\
\hline Substrate conc. $(\mathrm{g} / \mathrm{L})$ & $\mathrm{SC}$ & 10 & 30 & 50 \\
Incubation period $(\mathrm{h})$ & $\mathrm{IP}$ & 24 & 72 & 120 \\
$\mathrm{NaCl}(\mathrm{g} / \mathrm{L})$ & $\mathrm{NC}$ & 20 & 30 & 40 \\
Peptone $(\mathrm{g} / \mathrm{L})$ & $\mathrm{Pep}$ & 3 & 5 & 7 \\
Beef extract $(\mathrm{g} / \mathrm{L})$ & $\mathrm{BE}$ & 1 & 3 & 5 \\
$\mathrm{pH}$ & $\mathrm{pH}$ & 7 & 8 & 9 \\
Inoculum size $(\mathrm{ml})$ & $\mathrm{IS}$ & 1 & 3 & 5 \\
\hline
\end{tabular}

\subsection{Verification of Plackett-Burman Experiment}

In order to validate the obtained results and to evaluate the accuracy of the applied Plackett-Burman statistical design, a verification experiment was carried out in triplicates. According to the main effect results, the predicted near optimum and far from optimum levels of the independent variables were examined and compared to the basal condition settings. The enzymes activity and reducing sugar concentration were then estimated as described before (Plackett and Burman; 1946, Yu et al., 1997).

\subsection{Reducing Sugar Estimation by High Performance Liquid Chromatography (HPLC)}

The concentration of monosaccharides obtained from predicted near optimum conditions were measured by HPLC. The Shimpack SPR-Ca column (Shimadzu, Japan) at $80^{\circ} \mathrm{C}$ with IR-detector was used. The mobile phase was distilled water at a flow rate of $0.5 \mathrm{ml} / \mathrm{min}$. The samples were filtered with $0.45 \mu \mathrm{m}$ of cellulose acetate filter and $10 \mu \mathrm{l}$ of injection volume was added.

\section{Results}

\subsection{Characterization of the Promising Marine Bacterial Isolate}

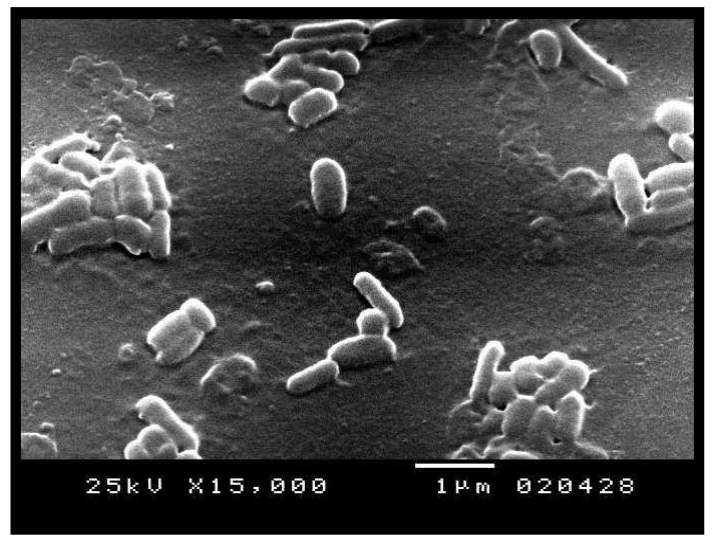

Figure 1. Scanning electron microscopic feature of bacterial isolate WM21 shown as rods.

The most promising marine bacterial isolate (WM21) was submitted to the phenotypic characterization through morphological, physiological and biochemical tests and submitted to genotypic characterization through $16 \mathrm{~S}$ rDNA technique.

It grew at $20-45^{\circ} \mathrm{C}, \mathrm{pH}$ range (6-10) and at all examined sodium chloride tested concentrations (0-10\%) Also catalase and oxidase are positive. Moreover, produce gelatinase, amylase, agarase, lipase (Tween 80), and lysine decarboxylase. In addition to, it was utilizing of glucose.

It has been found that the bacterial isolate WM21 had $96 \%$ identical counterpart with respect to $16 \mathrm{~S}$ rRNA sequence. Sequence of the isolate WM21 was affiliated according to their 16S rDNA to the genus Pseudoalteromonas. However, the isolate WM21 showed $96 \%$ sequence homology to Pseudoalteromonas piscicida.

Table 3. Accession number of the experimental $16 S \mathrm{rDNA}$ sequence and similarity percentage to the closest known species.

\begin{tabular}{lll}
\hline Accession no. & Most related Species & Similarity (\%) \\
\hline 359805839 & Pseudoalteromonas piscicida & 96 \\
\hline
\end{tabular}

\subsection{Chemical Cmposition of Algal Substrate}

The chemical analysis for the algal species; U. lactuca was carried out and the content of organic matter included the total carbohydrates, lipids, proteins and ash percentages were detected (Table 4).

Table 4. The chemical composition of different algal substrates.

\begin{tabular}{ll}
\hline Composition (\%) & U. lactuca \\
\hline Moisture content & 10 \\
Organic matter & 77 \\
Carbohydrate & 44 \\
Lipid & 5 \\
Protein & 16 \\
Fibers & 12 \\
Ash & 23 \\
\hline
\end{tabular}




\subsection{Optimization of Saccharification Process by Plackett- Burman Design}

Seven factors were examined as independent variables affecting the production of reducing sugars by $P$. piscicida. The symbols and level of these factors were presented in Table 2, while their distribution in nine major trails according to fitted design and their responses were shown in Table 5. Data conducted that the highest concentration of reducing sugar recorded $144 \mathrm{mg} / \mathrm{g}$ by trial No.6 with maximization of $41 \mathrm{mg} / \mathrm{g}$ comparing to the basal condition $103 \mathrm{mg} / \mathrm{g}$. The main effect data presented in Table 6 as well as the t-test results in suggested that the beef extract is the most effective variable that controlled the reducing sugar value by $P$. piscicida. The main effect of each variable, based on the reducing sugar concentration, was estimated as the difference between both averages of measurements made at the high level (+) and the low level (-) and represented graphically in Figure 2. The main effect data presented in Table 6 as well as the $t$-test results suggested that the beef extract and inoculum size are the most effective variables that controlled the reducing sugar produced by $P$. piscicida. According to these results, the lower inoculum size $(1 \mathrm{ml})$ and the higher beef extract $(5 \mathrm{~g} / \mathrm{L})$ are nearer to optimum than their opposite levels. Considerable positive effects of the high levels of substrate concentration and low levels of incubation period are also suggested by Figure 2. On the other hand, variations within the examined levels of $\mathrm{pH}$ levels, $\mathrm{NaCl}$ and peptone recorded slight effects. While the main effect data presented in Table 6 as well as the $t$-test results suggested that the substrate concentration and incubation period are the most effective variables that controlled amylase activity produced by $P$. piscicida. According to these results, the lower incubation period $(24 \mathrm{~h})$ and the higher substrate concentration $(5 \%)$ are nearer to optimum than their opposite levels. Considerable of the low levels of $\mathrm{pH}$ and the high levels of peptone are positive effect also suggested by Figure 3. On the other hand, variations within the examined levels of beef extract, $\mathrm{NaCl}$, and inoculum size recorded slight effects. The interacting effects of beef extract and substrate concentration as described in three-dimensional graph (Figure 4; A), suggest that, within the examined ranges the higher beef extract accompanied by the higher substrate concentration would markedly increase the reducing sugar expressed by the experimental bacterium; $P$. piscicida. However, the interaction beef extract and inoculum size (Figure 4; B) with respect to production of the reducing sugar appeared to be high.

Table 5. Applied Plackett-Burman design for seven cultural variables and the experimental results of reducing sugar produced by P. piscicida.

\begin{tabular}{|c|c|c|c|c|c|c|c|c|c|}
\hline \multirow{2}{*}{ Trial No. } & \multicolumn{7}{|c|}{ Independent variables } & \multirow{2}{*}{ Reducing sugar conc. (mg/g) } & \multirow{2}{*}{ Amylase (mm) } \\
\hline & SC & IP & $\mathrm{NC}$ & Pep & BE & pH & IS & & \\
\hline 1 & - & - & - & + & + & + & - & 110 & 21 \\
\hline 2 & + & - & - & - & - & + & + & 92 & 28 \\
\hline 3 & - & + & - & - & + & - & + & 90 & 18 \\
\hline 4 & + & + & - & + & - & - & - & 106 & 29 \\
\hline 5 & - & - & + & + & - & - & + & 80 & 23 \\
\hline 6 & + & - & + & - & + & - & - & 144 & 32 \\
\hline 7 & - & + & + & - & - & + & - & 70 & 15 \\
\hline 8 & + & + & + & + & + & + & + & 116 & 27 \\
\hline 9 & 0 & 0 & 0 & 0 & 0 & 0 & 0 & 103 & 29 \\
\hline
\end{tabular}

Table 6. Statistical analyses of the Plackett-Burman experimental results.

\begin{tabular}{lllll}
\hline & \multicolumn{2}{l}{$\begin{array}{l}\text { Reducing sugar conc. } \\
\text { (mg/g) }\end{array}$} & \multicolumn{2}{l}{ Amylase (mm) } \\
\cline { 2 - 5 } Variable & $\begin{array}{l}\text { Main } \\
\text { effect }\end{array}$ & t-value $^{\mathbf{1}}$ & Main effect $^{*}$-value $^{\mathbf{1}}$ \\
\hline Substrate conc. (\%) & 27 & 1.943 & 9.75 & 2.015 \\
Incubation period (h) & -11 & 2.015 & -3.75 & 2.015 \\
NaCl (g/L) & 3 & 2.013 & 0.25 & 1.943 \\
Peptone (g/L) & 4 & 2.013 & 1.75 & 2.131 \\
Beef extract (g/L) & 28 & 2.015 & 0.75 & 1.943 \\
pH level & -8 & 1.943 & -2.75 & 1.943 \\
Inoculum size (ml) & -13 & 2.013 & -0.25 & 2.015 \\
\hline
\end{tabular}

${ }^{1} t$-value significant at the $1 \%$ level $=3.70$

$t$-value significant at the $5 \%$ level $=2.446$

$t$-value significant at the $10 \%$ level $=1.94$

$t$-value significant at the $20 \%$ level $=1.372$

Standard $t$-values are obtained from Statistical Methods (Snedecor and Cochran 1989).

The interacting effects of substrate concentration and incubation period as described in three-dimensional graph (Figure 5; A) suggest that, within the examined ranges, the shorter incubation period accompanied by the higher substrate concentration would markedly increase the amylase activity expressed by the experimental bacterium; $P$. piscicida to activity of the amylase appeared to be very slight. However, the interaction of substrate concentration and $\mathrm{pH}$ level (Figure 5; B) with respect to activity of the amylase appeared to be very slight.

\subsection{Verification of Plackett-Burman Experiment}

In order to validate the obtained results and to evaluate the accuracy of the applied Plackett-Burman statistical design, a verification experiment was carried out in triplicates. The predicted near optimum and far from optimum levels of the independent variables were examined and compared to the basal condition settings. The Reducing sugar concentration and amylase activity of out using $P$. piscicida observations are shown in Table 7. The applied near optimum condition, resulted in approximately $56 \mathrm{mg} / \mathrm{g}$ increase in reducing sugar and $6 \mathrm{~mm}$ amylase activity by $P$. piscicida when compared to the basal medium formulation. On the other hand, the condition predicted to be far from optimal recorded 
approximately $45 \mathrm{mg} / \mathrm{g}$ decreases in reducing sugar and 3 $\mathrm{mm}$ amylase activity. These results support the predictions predicted from the applied Plackett-Burman experiment.

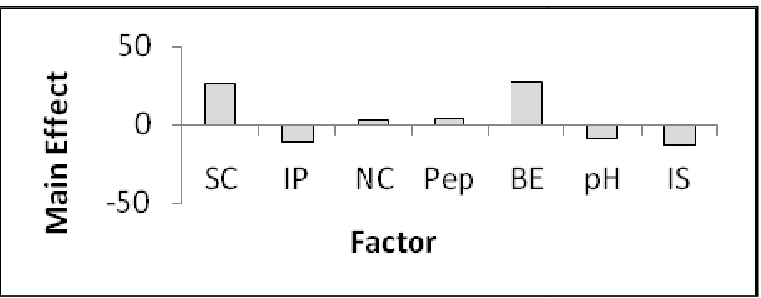

Figure 2. Elucidation of the factors affecting the production of reducing sugars by P. piscicida.

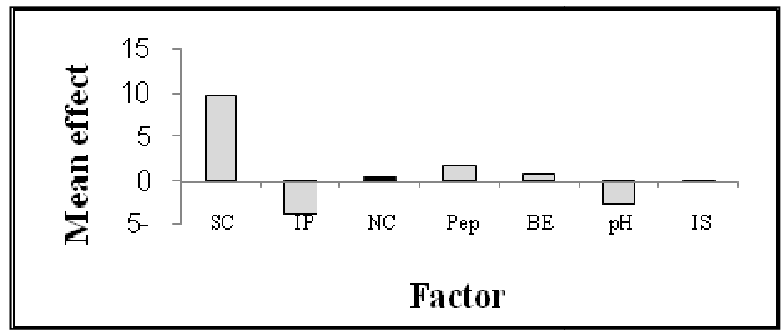

Figure 3. Elucidation of the factors affecting the amylase activity by $P$. piscicida.
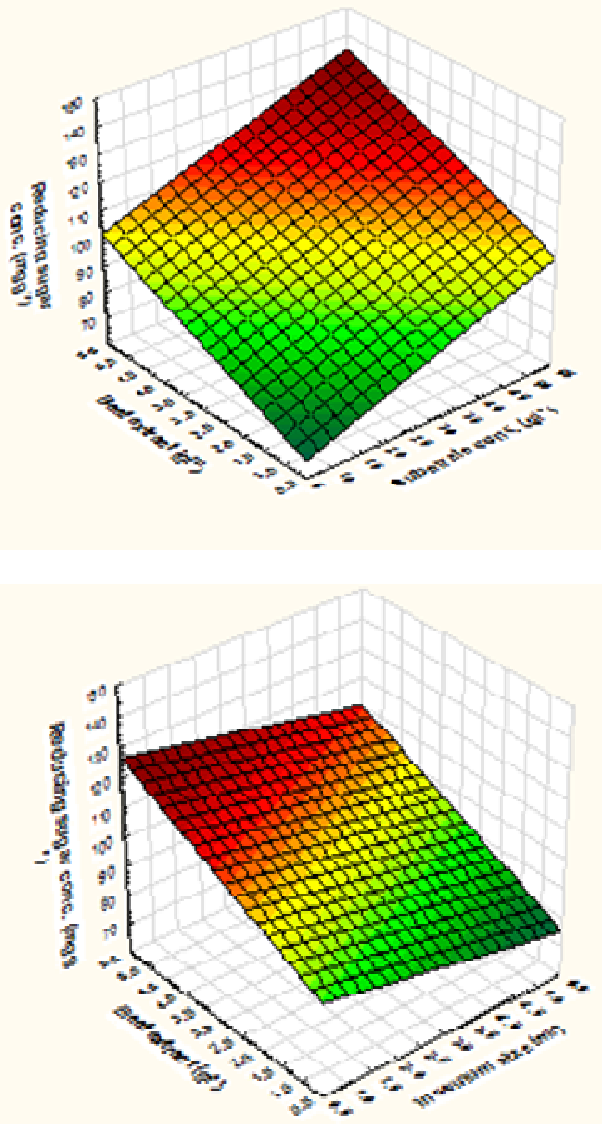

Figure 4. The response 3D Surface Polt analysis show the interaction of the different beef extract with different substrate concentration $(A)$ and different inoculum size (B) in relation to reducing sugar $\mathrm{mg} / \mathrm{g}$ by P. piscicida.
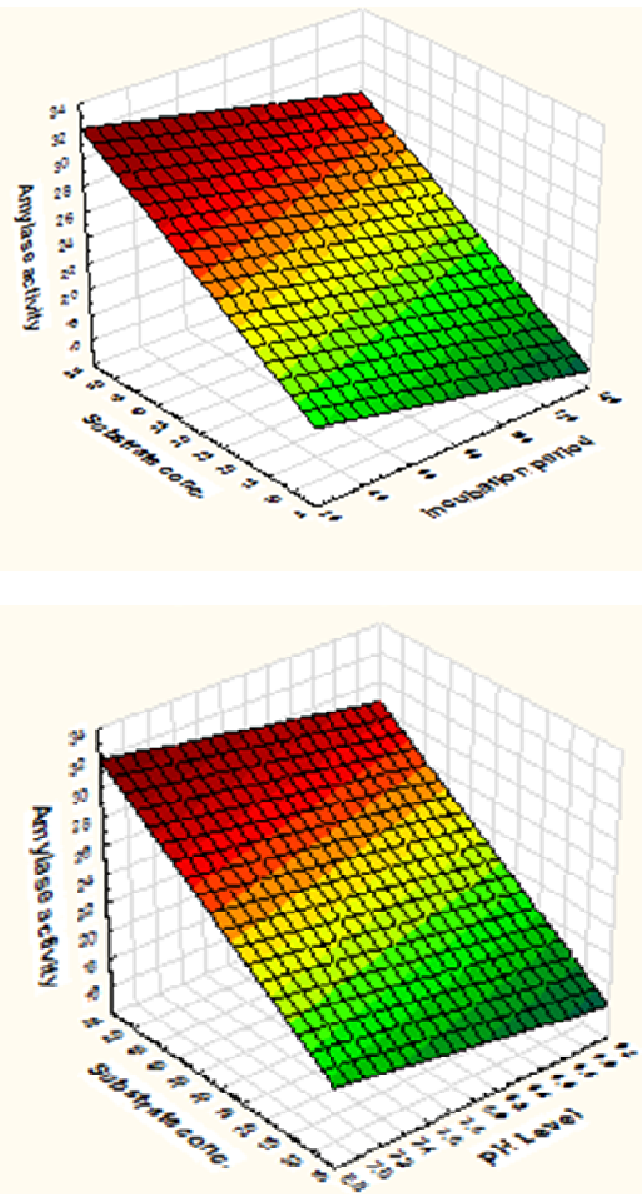

Figure 5. The response 3D Surface Polt analysis show the interaction of the different substrate concentration with different incubation period (upper) and different $\mathrm{pH}$ level (lower) in relation to amylase activity by P. piscicida.

Table 7. Verification of the Plackett-Burman experimental results that carried out using P. piscicida.

\begin{tabular}{llll}
\hline $\begin{array}{l}\text { Response } \\
\text { (Average) }\end{array}$ & $\begin{array}{l}\text { Basal } \\
\text { medium }\end{array}$ & $\begin{array}{l}\text { Near optimum } \\
\text { medium }\end{array}$ & $\begin{array}{l}\text { Far from optimum } \\
\text { medium }\end{array}$ \\
\hline $\begin{array}{l}\text { Reducing sugar } \\
\text { conc. (mg/g) }\end{array}$ & $102.3 \pm 0.007$ & $158 \pm 0.005$ & $57 \pm 0.005$ \\
Amylase (mm) & $29.3 \pm 0.003$ & $35 \pm 0.005$ & $26.3 \pm 0.005$ \\
\hline
\end{tabular}

\subsection{The Reducing Sugar Analysis by HPLC}

The monosaccharides and their concentration were estimated in near optimum medium using HPLC Glucose and galactose were detected at $144 \mathrm{mg} / \mathrm{g}$ and $24 \mathrm{mg} / \mathrm{g}$ respectively (Figure 6). 


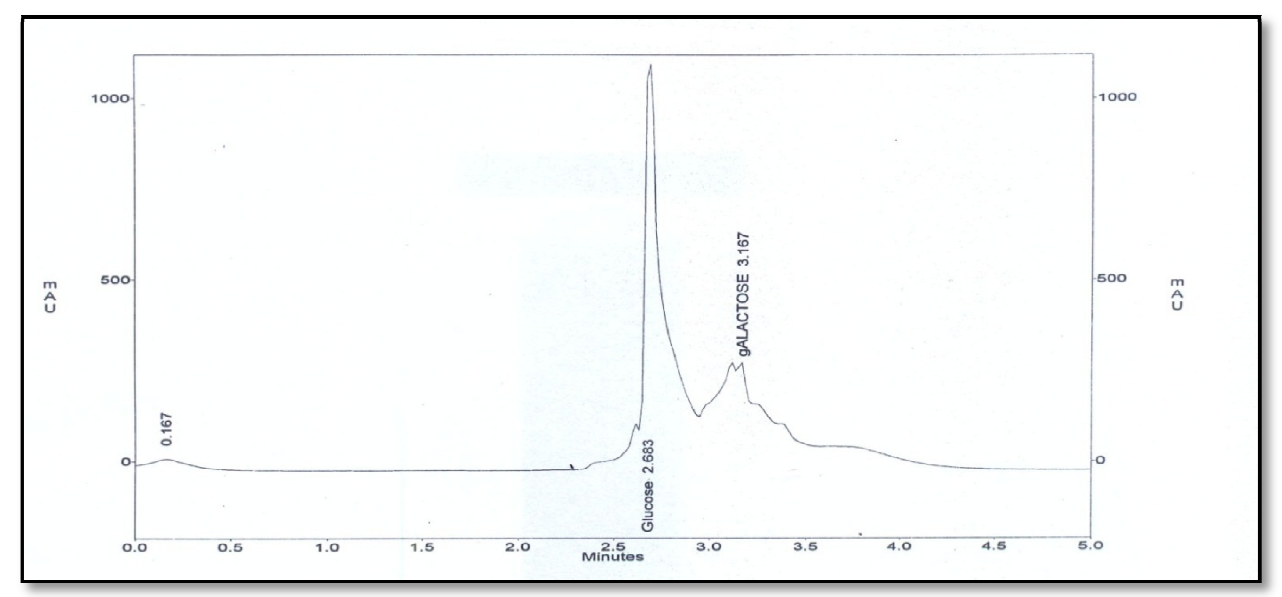

Figure 6. HPLC chromatogram showing glucose and galactose concentrations produced from U. lactuca hydrolysis by P. piscicida at retention time 2.68 and 3.17 min, respectively.

\section{Discussion}

Macroalgae are gaining some attention as an alternative renewable source of biomass for the production of bioethanol (Borowitzka, 1992). Some algae were represented to have high contents of carbohydrate that can be used as substrate for bioethanol production (Singh and Olsen, 2011). They also contain a low concentration of lignin (Wi et al., 2009) or no lignin at all (Ge et al., 2011). Therefore, the biomass of marine algae can be converted economically into simple sugars and then to bioethanol (Chynoweth, 2002; Sluiter, 2006; John et al., 2011).

The green macroalga; Ulva lactuca is appropriate substrate that contain $44 \%$ carbohydrates.

The marine bacterium WM21 exhibited promising enzymatic hydrolysis of polysaccharides. So, it was selected to be identified using phenotypic and genotypic analyses, respectively. It was gram-negative rod, grew at $20-45^{\circ} \mathrm{C}$ with $\mathrm{pH}$ range (6-10) and sodium chloride concentrations (2-10\%). Also, catalase and oxidase were positive. Moreover, it produced gelatinase, amylase, agarase, lipase (Tween 80 ), and lysine decarboxylase. In addition to, it was utilizing of glucose. This isolate genotypically was Pseudoalteromonas piscicida with similarity $96 \%$.

Actually, some workers isolated Pseudoalteromonas sp. and $P$. piscicida from different marine resources. For examples, Nelson and Ghiorse (1999) isolated P. piscicida from the diseased eggs of two damselfish (Pomacentridae) species; Amphiprion clarkii and Amblyglyphidodon curacao. As well as, Lau et al. (2005) isolated a Gram-negative, non-spore-forming, short rod-shaped bacterium (UST010723-006T) from the surface of the sponge Mycale adherents in Hong Kong waters. Cells of UST010723-006 did not have flagella and were nonmotile. Colonies were pale orange in color, $2-4 \mathrm{~mm}$ in diameter, convex with a smooth surface and an entire translucent margin. Gas bubbles were observed in the colonies and also in the agar matrix underneath and adjacent to the colonies. UST010723-006 was heterotrophic, strictly aerobic and required $\mathrm{NaCl}$ for growth (2-6\%). It grew at $\mathrm{pH} 5-10$ and between 12 and $44^{\circ} \mathrm{C}$. Phylogenetic analysis of the $16 \mathrm{~S}$ rRNA gene sequence placed UST010723-006T within the genus Pseudoalteromonas of the c-subclass of the Proteobacteria. These data supported the affiliation of UST010723-006T to the genus Pseudoalteromonas. The closest relatives were Pseudoalteromonas luteviolacea, $P$. phenolica, $P$. rubra and $P$. ruthenica with similarity values ranging from 95.4 to $96.8 \%$. Molecular evidence, together with phenotypic characteristics, suggests that UST010723-006T constitutes a novel species within the genus Pseudoalteromonas. The name Pseudoalteromonas spongiae $\mathrm{sp}$. is proposed for this bacterium.

Tao et al. (2008) examined the ability of $P$. piscicida and/or closely related species for hydrolytic enzymes secretion especially; amylase and agarase. They isolated marine bacteria producing extracellular $\alpha$-amylase from seawater and identified as member of Pseudoalterimonas species. Matsumoto et al. (2003) inoculated Pseudoalterimonas undina NKMB 0074 into suspensions containing the green microalgae NKG 120701 cells and increasingly reduced suspended sugars with incubation time. Terrestrial amylase and glucoamylase were inactive in saline suspension. They concluded that the marine amylase is necessary in saline conditions for successful saccharification of marine microalgae.

In a complementary step of optimization saccharification, the concentrations of medium components were simultaneously investigated using Plackett-Burman experiment design. Occasionally, seven factors were examined as independent variables affecting the production of reducing sugars by $P$. piscicida. Data conducted that the highest concentration of reducing sugar recorded $144 \mathrm{mg} / \mathrm{g}$ by trial No.6 with maximization of $41 \mathrm{mg} / \mathrm{g}$ comparing to the basal condition $(103 \mathrm{mg} / \mathrm{g})$ in trail No. 9 . And when applied the near optimum media we reached to reducing sugar production about $158 \mathrm{mg} / \mathrm{g}$.

By comparing these data $(158 \mathrm{mg} / \mathrm{g}$ equals $7.9 \mathrm{mg} / \mathrm{ml})$ with the reducing sugar ratio in other investigations, it was observed that our yield is was much more than that achieved by Malek et al. (1988) which was $(5.8 \mathrm{mg} / \mathrm{ml})$ obtained with a 
Cytophaga sp., using sugar cane bagasse as growth and hydrolysis substrates. While, Sunarti et al. (2010) obtained lower hydrolytic activity produced from cellulose fraction by isolate C4-4, which liberated $(3.5 \mathrm{mg} / \mathrm{ml})$ of total sugar. Yanagisawaa et al. (2011) used successive saccharification with an enzyme that was effectively used to obtain high concentrations of glucose from these seaweeds. They hypothesized that agar weed contained both galactan and glucan. For this reason, it was possible to obtain a high concentration of ethanol from agar weed using combined saccharification, which is the acid hydrolysis of galactan to produce galactose followed by the enzymatic hydrolysis of glucan to obtain glucose. Begum and Alimon (2011) pretreated three lignocellulosic substrates viz. sugarcane bagasse, sawdust and water hyacinth with alkali and enzyme and studied their effect on bioconversion agricultural and industrial wastes to chemical feedstock. They found that the maximum degree of conversion of substrate by Aspergillus oryzae ITCC $(0.415 \%)$ and improved specific substrate consumption $(0.99 \mathrm{~g}$ substrate/g dry biomass) was exhibited in sugarcane bagasse after alkali treatment at $96 \mathrm{~h}$. they observed that alkalitreatment and enzyme-treatment, water hyacinth was the best for cellulase induction and showed maximum endoglucanase activity of $11.42 \mathrm{U} / \mathrm{ml}$. Reducing sugar yield ranged from 1.12 $\mathrm{mg} / \mathrm{ml}$ for enzyme treated sawdust at $48 \mathrm{~h}$ to $7.53 \mathrm{mg} / \mathrm{ml}$ for alkali treated sugarcane bagasse at $96 \mathrm{~h}$. Alkali-treated sugarcane bagasse gave the highest saccharification rate of $9.03 \%$ after $96 \mathrm{~h}$. The most resistant substrate was sawdust which produced $5.92 \%$ saccharification by alkaline treatment.

However, the current study supports the following points:

1. Marine macroalgae (U. lactuca) can be used as promising substrates for the bioethanol production.

2. Pseudoalteromonas piscicida have ability to hydrolysis of U. lactuca substrate for production of reducing sugars.

3. Optimization of saccharification process enhanced the reducing sugars production.

\section{References}

[1] AOAC (Association of Analytical Chemists), (2000). Official Methods of Analysis of Association of Analytical Chemist. Horwitz, W., Gaithersburg, Maryland, USA.

[2] Austin, B. (1988). The marine environment. In: Marine Microbiology, (pp.1-11). Cambridge: Cambridge University Press.

[3] Begum, M.F. and Alimon, A.R. (2011). Assessment of some wild Aspergillus species for cellulase production and characterization. African Journal of Microbiology Research, 5(27), 4739-4747.

[4] Borowitzka, M. (1992). Algal biotechnology products and processes - matching science and economics. J. Appl. Phycol; 4, 267-79.

[5] Box, G.E.P., and Draper, N. R. (1987). Empirical Model Building and Response Surfaces, John Wiley \& Sons, New York, NY.
[6] Carolissen-Mackacy, V., Arendse, G. and Hastings, J.W. (1997). Purification of bacteriocins of lactic acid bacteria: problems and proteins. Food Microbiol; 34, 1-16.

[7] Chynoweth, D.P. (2002). Review of Biomethane from Marine Biomass. Department of Agricultural and Biological Engineering, University of Florida, Gainesville, Florida, USA.

[8] El-Helow, E.R. and El-Ahawany, A.M. (1999). Lichenase production by catabolite repression resistant Bacillus subtilis mutants: Optimization and formation of an agro-industrial by product medium. Enz. Microbiol. Technol; 24, 325-331.

[9] Fritze, D., Flossdorf J. and Claus, D. (1990). Taxonomy of alkaliphilic Bacillus strains. International Journal of Systematic Bacteriology, 40, 92-97.

[10] Ganzon-Fortes, E.T. (1991). Characteristics and economic importance of seaweeds. In: Proceedings of the seaweed research training and workshop for project leaders. Philippine Council for Aquatic and Marine Research and Development.

[11] Ge, L., Wang, P. and Mou, H. (2011). Study on saccharification techniques of seaweed wastes for the transformation of ethanol. Renewable Energy, 36, 84-89.

[12] Hong, L.S., Ibrahim, D. and Omar I.C. (2013). Effect of physical parameters on second generation bio-ethanol production from oil palm frond by Saccharomyces cerevisiae. BioResource, 8(1), 969-980.

[13] Horikoshi, K. (1999). Introduction: Definition of Alkaliphilic Organisms. In Alkaliphiles. (Kodansha Ltd., Tokyo, 1999b), p.1.

[14] Hu, Z., Lin, B.K., Xu, Y., Zhong, M.Q. and Liu, G.M. (2009) Production and purification of agarase from a marine agarolytic bacterium Agarivorans sp. HZ105. Journal of Applied Microbiology, 181-190.

[15] John, R.P., Anisha, G.S., Nampoothiri, K.M. and Pandey, A., (2011). Micro and macroalgal biomass: a renewable source for bioethanol. Bioresour Technol; 102, 186-93.

[16] Koppram, R., Nielsen, F., Albers, E., Lambert, A., Wännström, S., Welin, L., Zacchi, G. and Olsson, L. (2013). Simultaneous saccharification and co-fermentation for bioethanol production using corncobs at lab, PDU and demo scales. Biotechnology for Biofuels, 6, 2-10.

[17] Lau, S.C.K., Tsoi, M.M.Y., Li, X., Dobretsov, S., Plakhotnikova, Y. Wong, P-K. and Qian, P-Y. (2005). Pseudoalteromonas spongiae sp. nov., a novel member of the c-Proteobacteria isolated from the sponge Mycale adhaerens in Hong Kong waters. International Journal of Systematic and Evolutionary Microbiology, 55, 1593-1596.

[18] Malek, , N.A., , Q.M. and N. (1988). Bacterial cellulases and saccharification of lignocellulosic materials. Enzyme and Microbial Technology, 2, 750-753.

[19] Margesin, R., Gander, S., Zacke, G., Gounot, A.M. and Schinner, F. (2003). Hydrocarbon degradation and enzyme activities of cold-adapted bacteria and yeasts. Extremophiles, $7,451-458$.

[20] Matsumoto, M., Yokouchi, H., Suzuki, N., Ohata, H. and Matsunaga, T. (2003). Saccharification of Marine Microalgae Using Marine Bacteria for Ethanol Production. Applied Biochemistry and Biotechnology, 4(6): 105-108. 
[21] Miller, G.L., (1959). Use of dinitrosalicylic acid for determination of reducing sugar. Analytical Chemistry, 31, 426-428.

[22] Monaghan, R.L. and Koupal, L.R. (1989). Use of the Placket and Burman technique in a discovery program for new natural products. Novel Microbes: Products for Medicine and Agriculture, Chapter 2, 25-32.

[23] Myers, R.H. and Montgomery, D.C. (1995). Response surface methodology: process and product optimization using designed experiments. John Wiley and Sons Inc., New York, N.Y.

[24] Nelson, E.J. and Ghiorse, W.C. (1999). Isolation and identification of Pseudoalteromonas piscicida strain Cura-d associated with diseased damselfish (Pomacentridae) eggs. Journal of Fish Diseases, 22, 253-260.

[25] Ooijkaas, L.P., Wilkinson, E.C., Tramper, J. and Buitelaar, R.M., (1998). Medium optimization for spore production of Conithyrium minitans using statistically-Based experimental designs. Biotechlnol. Bioeng. 64 (1), 92-100.

[26] Pádua, M., Fontoura, P.S.G. and Mathias, A.L. (2004). Chemical Composition of Ulvaria oxysperma (Kützing) Bliding, Ulva lactuca (Linnaeus) and Ulva fascita (Delile). 47(1), 49-55.

[27] Park, J.I., Woo, H.C. and Lee, J.H. (2008). Production of bioenergy from marine algae: status and perspectives. Korean Chem. Eng. Res; 46 (5), 833-844.

[28] Philippidis, G..P, Smith, T.K., and Wyman, C.E. (1993). "Study of the Enzymatic Hydrolysis of Cellulose for Production of Fuel Ethanol by the Simultaneous Saccharification and Fermentation Process." Biotechnology and Bioengineering, 41, 846-853.

[29] Plackett, R.L. and Burman, J.P. (1946). The design of optimum multifactorial experiments. Biomrtrika, 33, 305-325.

[30] Ryther, J.H., Debusk, T.A. and Blakeslee, M. (1984). Cultivation and conversion of marine macroalgae (Gracilaria and Ulva). In: SERI/STR-231-2360, pp. 1-88.

[31] Singh, A. and Olsen, S.I. (2011). A critical review of biochemical conversion, sustainability and life cycle assessment of algal biofuels. Applied Energy, 88, 3548-3555.

[32] Sluiter, A. (2006). Determination of structural carbohydrates and lignin in biomass. Vol. Version 2006. National Renewable Energy Laboratory, USA. http://www.nrel.gov/biomass/analytical_procedures.html.

[33] Sun, Y. and Cheng, J. (2002). Hydrolysis of lignocellulosic materials for ethanol production: A review. Bioresour. Technol. 83(1): 1-11.
[34] Sunarti, T.C., Meryandini, A., Sofiyanto, M.E. and Richana, N. (2010). Saccharification of corncob using cellulolytic bacteria for bioethanol production. BIOTROPIA, 17( 2).

[35] Taherzadeh, M.J. and Karimi, K. (2008). Pretreatment of Lignocellulosic Wastes to Improve Ethanol and Biogas Production: A Review. International Journal of Molecular.

[36] Tao, X., Jang, M.S., Kim, K.S., Yu, Z. and Lee, Y.C. (2008). Molecular cloning, expression and characterization of alpha-amylase gene from a marine bacterium Pseudoalteromonas sp. MY-1. Indian J Biochem Biophys.;45(5), 305-309.

[37] Todorov, S., Giotcheva, B., Douset, X., Onno, B. and Ivanov, K. (2000). Influence of growth medium on bacteriocin production in Lactobacillus ptantarum ST31. Biotechnol. Equip; 14, 50-55.

[38] Todorov, S.D. and Dicks, L.M.T. (2004). Effect of medium components on bacteriocin production by Lactobacillus pentosus ST15/BR, a strain isolated from beer produced by the fermentation of maize, barley and soy flour. World J. Microbiol. Biotechnol; 20, 643-650.

[39] Trono, J.G.C. and Ganzon-Fortes, E. (1988). Philippine seaweeds. Philippines: National Book-store Inc.

[40] Ventosa, A. and Nieto, J.J. (1995). Biotechnological applications and potentialities of halophilic microorganisms. World J. Microbiol. Biotechnol; 11, 85-94.

[41] Wi, S.G., Kim, H.J., Mahadevan, S.A., Yang, D.J. and Bae, H.J., (2009). The potential value of the seaweed Ceylon moss (Gelidium amansii) as an alternative bioenergy resource. Bioresour Technol; 100, 6658-6660.

[42] Xiong, W., Li, X., Xiang, J. and Wu, Q. (2008). High-density fermentation of microalga Chlorella protothecoides in bioreactor for microbio-diesel production. Appl. Microbiol. Biotechnol; 78, 29-36.

[43] Yanagisawaa, M., Nakamuraa, K., Arigab, O. and Nakasakia, K. (2011). Production of high concentrations of bioethanol from seaweeds that contain easily hydrolyzable polysaccharides. Process Biochemistry, 46, 2111-2116.

[44] Yokoyama, M.Y. and Guimarães, O., (1975). Determinação dos teores de $\mathrm{Na}, \mathrm{K}, \mathrm{O}$ e proteínas em algas marinhas. Acta Biológica Paranaense, 4 (1/2), 19-24.

[45] Yu, X.S., Hallett, G., Sheppard, J. and Watson, A.K. (1997). Application of the Plackett-Burman experimental design to evaluate nutritional requirements for the production of Colletotrichum coccodes spores. Appl. Microbiol. Biotechnol; 47, 301-305. 